\section{Estudo \\ CoDebate}

em Testão

Planejamento
Revista Estudo \& Debate, Lajeado, v. 26, n. 3, 2019. ISSN 1983-036X

DOI: http://dx.doi.org/10.22410/issn.1983-036X.v26i3a2019.2103

\title{
COMPETITIVIDADE DAS EXPORTAÇÓES NO SETOR TÊXTIL E DE CONFECÇÓES DO BRASIL, NORDESTE E PERNAMBUCO
}

\author{
Mariana Zeferino dos Santos ${ }^{1}$, Monaliza de Oliveira Ferreira ${ }^{2}$
}

\begin{abstract}
Resumo: Em um mundo cada vez mais globalizado, o aumento da competitividade é considerado um objetivo a ser constantemente perseguido. Nesse contexto, a indústria têxtil e de confecção se destaca no Brasil por ser o $2^{\circ}$ maior empregador da indústria de transformação. A fim de explorar essa conjuntura, o objetivo do trabalho consistiu em analisar a competitividade das exportações no setor têxtil e de confecçóes do Brasil, Nordeste e Pernambuco no período de 1997 a 2017, a partir de índices de competitividade como o Índice de Gini-Hirschman, o Índice de Comércio Intrasetorial, Índice de Hirschman-Herfindahl e o Índice de Vantagem Comparativa Revelada. Os resultados indicaram que apesar de ter ocorrido um aumento no poder de mercado do Nordeste e diversos estados da Regiáo terem tido vantagem comparativa durante todo período analisado, o Estado de Pernambuco e o Nordeste como um todo náo aproveitaram muito bem as oportunidades que o comércio tem a oferecer, sendo necessário expandir os investimentos no setor, para se adquirir maior produtividade e competitividade frente ao mercado internacional.
\end{abstract}

Palavras-chave: competitividade internacional; setor têxtil e de confecçôes; Nordeste brasileiro; Pernambuco.

\section{COMPETITIVENESS OF EXPORTS IN THE TEXTILE AND GARMENT SECTOR OF BRAZIL, NORDESTE AND PERNAMBUCO}

\begin{abstract}
In an increasingly globalized world, increasing competitiveness is considered a goal to be constantly pursued. In this context, the textile and garment industry stands out in Brazil for being the 2nd largest employer in the manufacturing industry. In order to explore this situation, the objective of this work was to analyze the competitiveness of exports in the textile and clothing sector in Brazil, Northeast and Pernambuco from 1997 to 2017, based on competitiveness indexes such as the Gini-Hirschman Index, the Index of Intrasectoral Trade, Hirschman-Herfindahl Index and the Revealed Comparative Advantage Index. The results indicated that despite the fact that there has been an increase in the market power of the Northeast and several states in the Region have had a comparative advantage during the analyzed period, the State of Pernambuco and the Northeast as a whole did not take advantage of the opportunities that trade has to offer, being necessary to
\end{abstract}

1 Estudante de Economia na Universidade Federal de Pernambuco - Campus do Agreste. E-mail: mary.zeferino@gmail.com.

2 Professora do Programa de Pós-Graduação em Economia - PPGECON, da Universidade Federal de Pernambuco - Campus do Agreste. E-mail: monalizaoferreira@gmail.com. 
expand the investments in the sector, in order to achieve greater productivity and competitiveness in relation to the international market.

Keywords: international competitiveness; textile and clothing industry; Brazilian Northeast; Pernambuco.

\section{INTRODUÇÁO}

As transformaçóes nas economias nos últimos anos refletiram-se na necessidade de aumento da competitividade das indústrias frente ao mercado internacional. A literatura (Krugman, 1996; Bonelli e Pinheiro, 2012; Costa, 2012; Kupfer e Hasenclever, 2013; Lima, Lélis e Cunha, 2015) apresenta vários e diversos fatores que determinam a competitividade internacional. Tais fatores impactam de formas distintas nos diferentes segmentos produtivos.

Ao longo das cinco últimas décadas, o crescimento econômico do Brasil se caracteriza por fatos contraditórios, especialmente diante do registrado em certos países em desenvolvimento na Ásia. Ao contrário do Brasil, bem como de toda a América Latina, os chamados tigres asiáticos e a China têm logrado manter processo sustentado de "catching $u p^{3 "}$. Este se acelerou em seguimento ao impulso de industrialização, como no caso do Brasil, mas logrou persistir em bases mais sólidas, apesar dos efeitos adversos de choques externos e das crises financeiras na Ásia, em fins da década de noventa. Esses fenômenos causaram menores danos e descontinuidades ao crescimento naqueles países do que nos latino-americanos (SARQUIS, 2011).

O Sul-Sudeste concentra a grande maioria das empresas exportadoras do País. No Nordeste destacam-se o Polo Têxtil de Pernambuco e o do Ceará, mas nesta Região não há cultura exportadora expressiva. As exportações brasileiras do setor representam 8\% do mercado mundial e são destinadas principalmente a Argentina e Estados Unidos, concentrando a maior parte deste comércio em fibras têxteis (tecidos). Considerando-se o setor de confecçóes isoladamente, que em que o Brasil representa 6\% do comércio mundial, vê-se que os principais mercados do País são Paraguai, Estados Unidos e Uruguai. Ressalte-se que a linha lar é o maior responsável pelas exportaçóes de confecçóes e o setor de vestuários representa apenas 14,5\% desse comércio (BRADESCO, 2017).

De acordo com a Associação Brasileira da Indústria Têxtil e de Confecção (ABIT), em 2017 o País teve um faturamento de US\$ 45 bilhōes no setor, contra US\$ 39,3 bilhões em 2016. O setor ainda é o $2^{\circ}$ maior empregador da indústria de transformação, perdendo apenas para alimentos e bebidas (juntos) e o $2^{\circ}$ maior gerador do primeiro emprego, em uma indústria que tem quase 200 anos no País, sendo referência mundial em design de moda praia, jeanswear e homewear.

O setor é pulverizado e concorrencial, mas como a maioria das empresas brasileiras do setor é de pequeno porte e do tipo familiar, especialmente no Nordeste, aspecto que dificulta a adoção de técnicas modernas de administração e controle, além do fator informalidade,

3 Entende-se por convergência (catching-up), o processo em que as economias em desenvolvimento se aproximam do nível de riqueza acumulada das economias mais desenvolvidas. 
muito presente no setor. De forma que, apesar de o Brasil ter uma produção de destaque mundial e o Nordeste ter destaque na participação desta produção, sua inserção comercial é muito reduzida. Para explicar esse quadro, tem de se verificar a competitividade das empresas. Mas há questóes históricas que explicam o cenário competitivo das empresas e, por conseguinte, do fluxo comercial brasileiro com o exterior. De um lado, um processo de colonização onde se destinavam os produtos primários para a corte portuguesa; e de outro, em tempos mais atuais, a orientação da política econômica para o processo de substituição de importaçóes (WOOD JR; CALDAS, 2007). Isso justifica os números das exportaçóes voltados quase que exclusivamente para o comércio de commodities agrícolas no País. De um tempo, com o fortalecimento da indústria nacional, o País começou a investir em produtos manufaturados. E hoje já se observa na pauta de exportaçóes brasileiras, ainda que em menor participação, produtos capital intensivos e de maior valor agregado.

Celso Furtado (2007) demonstrou que a política econômica voltada para o processo de substituição de importaçóes teve início na década de 1930, e consistia em aumentar a produção interna do país e diminuir suas importaçóes. Dessa forma, com o foco nas indústrias nacionais, buscava-se evitar os déficits no balanço de pagamentos causados pela Grande Depressão de 1929. No entanto, Teixeira (2007) acrescentou que a partir de 1990 esse modelo protecionista perdia força diante de um mundo capitalista competitivo e globalizado. Com a abertura geral da economia brasileira, surgiram novos desafios para toda a indústria do País, devido ao aumento da exposição aos competidores externos, o que forçou a indústria nacional a aprimorar seus produtos e seus métodos de produção. Nessa nova realidade, era necessário ter como referência o comércio global e não mais o mercado interno.

A preocupação do Brasil em se inserir no comércio exterior veio da constatação de que os países com economias mais abertas experimentaram maior progresso material e social se comparados a países com economias fechadas (WILLIAMSON, 1989; GALVÃO E VERGOLINO, 2004). Munduruca e Santana (2012) exemplificaram essa ideia ao explicar que a expansão das exportaçóes pode gerar um efeito multiplicador sobre as atividades do mercado interno, criando uma maior demanda por serviços e melhorando a renda e o nível de emprego da população.

$\mathrm{Na}$ indústria têxtil, o impacto inicial da abertura da economia nacional foi de crise, pois o setor ainda estava atrasado tecnologicamente por causa do protecionismo anterior. Além disso, durante o aumento das importações de fios e tecidos sintéticos e artificiais, as exportaçóes permaneciam constantes, o que gerou conflito entre diversos elos da cadeia. As empresas de pequeno e médio porte tinham poucas chances de continuar, pois eram pouco modernizadas. Dessa forma, a tendência era a ascensão das grandes empresas, pois elas tinham melhores condiçóes de conseguir investir em tecnologia (KELLER, 2006).

Já Pernambuco, entre 1996 e 2002, ainda era considerado um Estado fechado para o comércio internacional. Isso se dava por causa da implementação de barreiras pelos países industrializados ou pela propensão das empresas em atender o mercado interno. No entanto, o governo do Estado passou a incentivar o comércio internacional através da infraestrutura, como com a criação do Porto de Suape, buscando aumentar as exportaçóes, diminuir custos, desenvolver vantagens competitivas e aproveitar os recursos naturais (MACIEL, 2011) 


\subsection{Objetivos}

O objetivo do trabalho consistiu em analisar a competitividade das exportaçóes no setor têxtil e de confecçóes do Brasil, Nordeste e Pernambuco, no período de 1997 a 2017, a partir de indicadores de competitividade consagrados na literatura sobre comércio internacional.

Os objetivos específicos consistiram em calcular e analisar quatro indicadores de competitividade: o Índice de Gini-Hirschman, o Índice de Comércio Intrasetorial, Índice de Hirschman-Herfindahl e o Índice de Vantagem Comparativa Revelada.

Além disso, esse projeto contribuiu para uma pesquisa maior que trata das possibilidades e limitaçóes do setor têxtil e de confecçóes de Pernambuco para a inserção competitiva no mercado internacional, consolidando mais uma pesquisa no Grupo de Pesquisa em Economia Aplicada e Desenvolvimento Sustentável (GPEADS).

\section{REFERENCIAL TEÓRICO}

De forma geral, os países participam do comércio internacional por duas razóes: buscam ganhos de comércio, ou seja, um arranjo onde cada país produz aquilo no qual ele é melhor; e buscam economias de escala, pois ao produzir uma variedade limitada de bens é possível se tornar mais eficiente na produção deles (Krugman e Obstfeld, 2009). Com base nisso, os elementos teóricos que servem de fundamento para a realização deste trabalho estão baseados em duas teorias complementares: Teoria da Vantagens Comparativas e Teoria Heckscher-Ohlin (H-O).

\subsection{Marco Teórico: Teoria das Vantagens Comparativas e Teoria Heckscher-Ohlin (H-O)}

No livro "Princípios de Economia Política e Tributação" (1996), David Ricardo demonstrou que é possível existir comércio entre naçóes mesmo sem haver vantagem absoluta na produção de algum bem. Para explicar como se dá esse comércio, o economista usa a teoria das vantagens comparativas. Nesse caso, a nação deverá se especializar na produção do bem que possuir menor desvantagem absoluta. Com isso, os dois países saem ganhando na comercialização de bens onde vantagem comparativa ocorre por causa de ganhos de eficiência.

Em outras palavras, existe vantagem comparativa quando um país escolhe produzir um bem no qual seu custo de oportunidade é menor e não, necessariamente, no qual seu custo absoluto é menor. Isso significa que um país pode ser menos eficiente na produção de ambos os bens e ainda assim promover um comércio benéfico para ambos. Para isso, o país deve exportar o bem no qual tem menor desvantagem absoluta e importar o bem onde sua desvantagem absoluta é maior (SALVATORE, 2007).

Para David Ricardo, essa vantagem está onde a necessidade unitária de trabalho é menor. Com isso, os países se especializam e obtém ganhos do comércio, pois seu trabalho será mais eficiente e ele poderá comprar o restante que precisa a preços mais baixos do que se fosse produzido internamente. Logo, o comércio entre dois países pode beneficiar ambos. 
No entanto, é preciso levar em conta que a especialização nos países não chega ao extremo, pois existem barreiras causadas pelo protecionismo, levando a uma distribuiçáo desigual dos benefícios do comércio, e barreiras físicas, como o custo do transporte (MACIEL, 2011).

De acordo com Gonçalves (1998), a teoria das vantagens comparativas demonstra que o comércio bilateral é sempre melhor se comparado a uma situação de autarquia quando dois países possuem estruturas de produção diferentes. Ou seja, é necessário que as quantidades relativas de trabalho para a produção de cada bem sejam diferentes para o comércio exterior ser vantajoso. As vantagens comparativas seriam resultantes do aproveitamento de diferenças nas dotaçôes do fator de produção trabalho.

Um ponto controverso envolvendo essa teoria é considerar que a concorrência é prejudicial e injusta quando se baseia em baixos salários. A China, por exemplo, tem vantagem nesse requisito, pois possui salários baixos se comparado ao mercado mundial. No entanto, Krugman e Obstfeld (2009) afirmaram que não importa se o custo mais baixo de produzir determinado bem vem da alta produtividade ou de salários mais baixos. O ponto central é que é produzir esse determinado bem é mais barato em relação ao seu próprio trabalho e, com isso, é possível comercializar esse bem por outro, em vez de produzir ambos os bens.

Ainda, Krugman e Obstfeld (2009) desmistificaram mais duas ideias equivocadas sobre as vantagens comparativas. O livre comércio apenas é benéfico para a nação que for forte o bastante para enfrentar a concorrência com o restante do mundo; e quando os salários de uma determinada nação são muito menores que das demais, o comércio irá explorar essa nação e torná-la pior. No primeiro caso, os autores argumentaram que na teoria das vantagens comparativas não é preciso ter vantagem absoluta para o comércio ser vantajoso. Já no segundo caso, o argumento é rebatido com a seguinte pergunta: "os trabalhadores e a nação estariam em uma situação pior se exportassem bens baseados em baixos salários ou se não estivessem nesse comércio depreciativo?" Para os autores, se essa nação não exportasse poderia estar em uma situação ainda pior.

Então, a partir dessa noção de vantagem comparativa, surge a Teoria de HeckscherOhlin (H-O) ou "Teoria de proporçóes de fatores", que afirma que a vantagem comparativa é dada pelas diferenças de terra, capital, recursos minerais e trabalho. E esses fatores serão os principais elementos que explicaráo os ganhos de comércio. Isso significa que uma nação será mais eficiente à medida que o país seja mais favorecido em relação aos fatores de produção necessários para a produção de um bem. Ou seja, um país irá exportar fatores abundantes e baratos; e importará recursos considerados escassos e caros no país. Por esta teoria, o comércio também permite que todos saiam ganhando, pois expande as escolhas da economia e melhora a distribuição da renda. Se não existisse o comércio, o consumo estaria limitado pela fronteira de possibilidade de produção, ou seja, o país teria uma economia autossuficiente. Com o comércio, a troca entre os países permite que as pessoas consumam mais de vários bens baseados na restrição orçamentária, e todos saem ganhando (KRUGMAN; OBSTFELD, 2009).

Os pressupostos dessa teoria consistem na existência de dois fatores de produção (capital e trabalho) para duas naçóes; ambas naçóes possuem disponibilidade de tecnologia; a commodity x é intensiva em mão de obra intensiva e a commodity y é intensiva em capital; 
x e y são produzidas sob retornos constantes de escala; a especialização não é total ou completa; os padróes de preferência nas nações são idênticos; a concorrência é perfeita; existe mobilidade perfeita dos fatores de produção, porém, não há mobilidade internacional dos fatores, assim como não existe custos, tarifas e obstáculos ao comércio; os recursos são totalmente ocupados e o comércio internacional encontra-se em equilíbrio (PROCÓPIO et al., 2011).

Krugman e Obstfeld (2009) fizeram uma observação em relação ao fato da equalização de preços ser alcançada pelo comércio entre os dois países. Para eles, a convergência de preços ocorre por causa de barreiras comerciais (como a fixação de tarifas e cotas de importação), e não devido a barreiras naturais (como custo com transporte).

Comparando as teorias, pode-se observar que a teoria $\mathrm{H}-\mathrm{O}$ se diferencia do modelo ricardiano na forma que determina os fatores que explicam a existência das vantagens comparativas.

Levando em consideração essas fundamentações teóricas, esta pesquisa parte do pressuposto que o comércio internacional é benéfico para os países, por isso é importante aumentar o grau de abertura do País.

\subsection{Revisão da Literatura}

Segundo Lima (2006), a teoria das vantagens comparativas é usada por correntes que defendem o livre comércio como forma de eliminar ineficiências ligadas à proteção comercial dos países. Isso se daria por meio do aumento da especialização e dos ganhos de escala na produção, que permitiria uma expansão das inovaçóes tecnológicas e do aprendizado de forma que o bem-estar geral seria alcançado. O livre comércio também garantiria que nenhum tipo de intervenção fosse usada para favorecer setores politicamente influentes. Com base nessa visão, seria possível medir a evolução de um país a partir do grau de abertura da sua economia, medido pela relação entre as exportaçóes e o Produto Interno Bruto (PIB).

Atualmente, o Brasil ainda possui baixa inserção no comércio internacional e ineficiência na competitividade. Segundo o Relatório de Competitividade Global do Fórum Econômico Mundial - FEM, divulgado em setembro de 2017, o Brasil está na 80a posição entre os 137 países analisados (FEM, 2018). Essa posição reflete alguns dos obstáculos internos que a expansão das exportaçóes ainda enfrenta. Como citado por Lima (2006), a ausência de cultura exportadora teria como causa a herança do modelo de substituição de importaçóes, mas outros fatores impactantes também poderiam ser levantados, como o fato de não se ter infraestrutura adequada com ferrovias e portos para grandes volumes no País, o custo do crédito ser elevado e desencorajar um crescimento alavancado, o sistema tributário ser custoso e não se converter para o bem-estar social, náo ter mão de obra qualificada e integrada ás empresas, dentre outros obstáculos.

Para Costa (2014), a fragmentação dos processos produtivos (onde as empresas separam as etapas de produção em diversos países) também dificultaria uma inserção dinâmica no comércio internacional. Isso porque as multinacionais ficam com atividades de maior valor agregado, como pesquisa e desenvolvimento, em seus países, enquanto as 
atividades de menor valor agregado são terceirizadas para países que, geralmente, estão em desenvolvimento, onde o Brasil se encaixa. Portanto, nesse processo nem todos os países conseguem ter os mesmos benefícios, já que seus ganhos dependem do seu posicionamento na divisão da produção.

Medeiros (2008) também encontrou resultados similares e concluiu que os ganhos vindos da participação na produção dependem do posicionamento dos países nas cadeias globais de produção. O processo de fragmentação produtiva tende a favorecer principalmente os detentores de ativos intangíveis como pesquisa e desenvolvimento, marca, desenho e concepção na apropriaçáo de valor, enquanto que as atividades mais padronizadas e de menor qualificação ficam concentradas em um pequeno conjunto de indústrias.

O Nordeste não fugiria à regra do restante do País. Fontenele e Melo (2003) afirmaram que seria um desafio redirecionar as exportaçōes para produtos com maior valor agregado. Lima (2006) concluiu a mesma ideia ao pesquisar a inserçáo internacional do Nordeste brasileiro, em especial Bahia, Ceará e Pernambuco, afirmando que as exportaçóes do Nordeste não conseguem competir igualmente com as produçôes dos Estados Unidos e da Europa, pois seu valor agregado é baixo comparado a alta tecnologia das regióes mais desenvolvidas. Na verdade, esta competição já é difícil dentro do próprio País, comparandose Nordeste e Sudeste.

Em Pernambuco, Maciel (2011) pontuou algumas iniciativas com o objetivo de inserir o Estado no comércio internacional, como o Porto de Suape, que tem atraído um capital estrangeiro significativo e grandes empresas internacionais. $\mathrm{O}$ que se esperava era que o processo de abertura comercial contribuísse com o surgimento de novas empresas e, consequentemente, com a geração de emprego e aumento de renda. Portanto, a realidade de Suape reanimaria esta expectativa. Além disso, a importaçáo de bens de capital incentivaria a produçáo de novos produtos e a diversificaçáo da pauta exportadora do Estado.

Ao analisar o padrão de comércio para saber qual a fonte de competitividade do Estado, Maciel (2011) concluiu que o comércio entre Pernambuco e o resto do mundo, no período de 2003 a 2010, seria caracterizado como sendo essencialmente interindustrial ou do tipo Heckscher-Ohlin. Isso significa que os ganhos do Estado se dáo pelo menor custo com os fatores de produção, principalmente o trabalho. Para a autora, esse resultado era esperado, pois a industrialização do Nordeste, de forma geral, está voltada para fornecer insumos e produtos finais para o Sudeste, tendo poucas ligaçóes com o comércio internacional. Isso implica que a regiáo não possui economia de escala, isto é, a produção náo pode ser dobrada sem que se dobre a quantidade de insumos, o que caracterizaria um comércio intraindustrial. Em relaçáo a estrutura das exportaçóes de Pernambuco, a pesquisadora encontrou que, no setor têxtil, o Estado tinha uma participação de 10,4\% em 2003, caindo para $1,75 \%$ em 2010, representando um crescimento negativo de $10,0 \%$ nesse intervalo. Essa queda deve-se a perda competitividade do setor em relação aos países asiáticos como Índia e China.

Silva et al. (2017) pesquisaram o padrão de especialização do comércio internacional de Pernambuco, a fim de identificar os setores produtivos mais dinâmicos, no período de 1999 a 2015. Os autores encontraram que pauta exportadora do Estado continua a ser predominantemente composta por setores baseados em recursos naturais. Além disso, na 
participação percentual das exportaçóes totais de Pernambuco, os setores que apresentaram menor crescimento foram alimentos/fumo/bebidas $(137,6 \%)$, calçados/couro $(21,3 \%)$ e têxtil $(-57,1 \%)$.

Marshall (1985) foi um dos primeiros a identificar outro fator que pode gerar uma maior eficiência para a produção em escala, que é a integração de empresas inter-relacionadas concentradas em um mesmo espaço geográfico. Essa concentração é definida por Porter (1999) como sendo um cluster. Nessa aglomeração acaba existindo uma combinação entre competição e cooperação, onde esse relacionamento dinâmico originou o neologismo “coopetição” proposto por Nalebuff e Brandenburger (1996) apud Caldeira et al (2017).

Isso se dá porque as empresas possuem várias necessidades que são difíceis de satisfazer de forma autônoma, mas podem ser atendidas pela cooperação. De acordo com essa ideia, a junção ou compartilhamento de recursos e capacidades irá potencializar o ganho de knowhow de mercado, o desenvolvimento e o aprimoramento de tecnologias, de produtos e de serviços e a redução de custos e riscos. Tudo isso irá ajudar a desenvolver competências para o setor operar em escala mundial (AMATO NETO, 2000).

Caldeira et al. (2017) pesquisaram entidades de classe, levando em conta que um dos mecanismos comuns de cooperação entre empresas de uma mesma indústria é justamente através da concepção das entidades de classe, que podem ser representadas por federaçóes, associaçóes, sindicatos patronais, etc. Dessa forma, entrevistaram sete executivos que atuam em funções estratégicas em entidades de classe de destacada atuação no setor têxtil e de confecçóes (como ABIT, COMTÊXTIL, ABRAFAS). Em seus resultados, ficou claro a influência das açóes das entidades de classes no incentivo da cooperação, que se dá através do diálogo que elas estabelecem com o governo nacional, pelo fornecimento de serviços que atendem às demandas específicas das empresas, pela parceria de trabalhos desenvolvidos com outras instituiçóes e pela criação de projetos com o objetivo de incentivar a competitividade do setor.

Lins (2015) também estudou a formação dos clusters, com foco nos setores de confecçóes e de couros e calçados nos municípios do Nordeste. O autor encontrou que o setor de confecçóes apresenta concentração espacial dos clusters produtivos nos Estados de Pernambuco, Ceará e Rio Grande do Norte. Além disso, também concluiu que o emprego formal do setor de confecçóes do Nordeste também está concentrado nesses três Estados, que, juntos representaram, em 2012, 78,71\% do emprego formal do setor.

\section{PROCESSO METODOLÓGICO}

O corte temporal dado para esta pesquisa compreendeu o período de 1997 a 2017. As variáveis utilizadas no estudo foram exportaçóes $(\mathrm{X})$ e importações $(\mathrm{M})$. A principal fonte de pesquisa foi a Secretaria de Exportação do Ministério da Indústria, Comércio Exterior e Serviços (SECEX/MDIC).

A caracterização do setor têxtil e de confecçóes no Brasil, Nordeste e Pernambuco foi realizada com base na análise dos dados de exportação $(\mathrm{X})$, importaçáo $(\mathrm{M})$ e saldo da balança comercial (X-S). A principal referência de dados para esta pesquisa referiu-se aos estudos econômicos do FMI (2000-2016), tendo como base o último estudo (FMI, 2016), 
bem como outros dados disponíveis nas fontes apresentadas. A abordagem metodológica para esta caracterização seguiu fundamentalmente Lima (2006), Maciel (2011) e Costa (2014).

Para analisar o grau de competitividade do setor têxtil e de confecçóes brasileiro, nordestino e pernambucano junto ao comércio exterior, nesse período de tempo, calculouse indicadores de competitividade como o Índice de Gini-Hirschman, o Índice de Comércio Intrasetorial, Índice de Hirschman-Herfindahl e o Índice de Vantagem Comparativa Revelada, a partir do arcabouço metodológico aplicado em Maia Neto (2013).

O Quadro 1 apresenta os capítulos selecionados da Nomenclatura Comum do Mercosul (NCM) relacionados ao setor têxtil e ao setor de confecçóes que foi usado para calcular os indicadores de competitividade.

Quadro 1 - Capítulos selecionados na NCM

\begin{tabular}{|c|c|}
\hline \multicolumn{2}{|r|}{ Setor têxtil } \\
\hline Capítulo & Descrição \\
\hline 50 & Seda \\
\hline 51 & Lã, pelos finos ou grosseiros; fios e tecidos de crina \\
\hline 52 & Algodão \\
\hline 53 & Outras fibras têxteis vegetais; fios de papel e tecidos de fios de papel \\
\hline 54 & $\begin{array}{l}\text { Filamentos sintéticos ou artificiais; lâminas e formas semelhantes de matérias } \\
\text { têxteis sintéticas ou artificiais }\end{array}$ \\
\hline 55 & Fibras sintéticas ou artificiais, descontínuas \\
\hline 56 & $\begin{array}{l}\text { Pastas (ouates), feltros e falsos tecidos; fios especiais; cordéis, cordas e cabos; artigos } \\
\text { de cordoaria }\end{array}$ \\
\hline 57 & Tapetes e outros revestimentos para pisos (pavimentos), de matérias têxteis \\
\hline 58 & Tecidos especiais; tecidos tufados; rendas; tapeçarias; passamanarias; bordados \\
\hline 59 & $\begin{array}{l}\text { Tecidos impregnados, revestidos, recobertos ou estratificados; artigos para usos } \\
\text { técnicos de matérias têxteis }\end{array}$ \\
\hline 60 & Tecidos de malha. \\
\hline \multicolumn{2}{|r|}{ Setor de confecçóes } \\
\hline Capítulo & Descriçáo \\
\hline 61 & Vestuário e seus acessórios, de malha \\
\hline 62 & Vestuário e seus acessórios, exceto de malha \\
\hline 63 & $\begin{array}{l}\text { Outros artefatos têxteis confeccionados; sortidos; artefatos de matérias têxteis, } \\
\text { calçados, chapéus e artefatos de uso semelhante, usados; trapos }\end{array}$ \\
\hline
\end{tabular}

Fonte: Elaboração própria, dados do BRASIL/MDIC/ALICEWEB (2018). 


\subsection{Indicadores de competitividade para o Brasil, Nordeste e Pernambuco}

Apontar produtos que possuem vantagem comparativa no comércio internacional auxilia na elaboração de estratégias para inserção internacional, proporcionando crescimento e bem-estar econômico para regiâo (Hidalgo e Da Mata, 2004). Sendo assim, os quatro indicadores a seguir foram utilizados para identificar o grau de competitividade do setor têxtil e de confecçóes brasileiro, nordestino e pernambucano:

a) Índice de Gini-Hirschman

$\mathrm{O}$ indicador mais utilizado para mensurar a concentração das exportações é o coeficiente de Gini-Hirschman. Outros indicadores, com finalidade similar, usados nessa pesquisa são: o Índice de Comércio Intrassetorial e o Índice Hirschman-Herfindahl.

Esse índice é dado pelo somatório do quadrado da participação do setor têxtil e de confecções nas exportações/importações totais de determinado estado, representado pela seguinte formula:

$$
\mathrm{ICP}=\sqrt{\sum_{i}\left(\frac{x_{i j}^{n}}{x_{j}^{n}}\right)^{2}}
$$

Onde:

$X_{i j}^{n}=$ representa o valor das exportaçóes/importaçóes do setor $i$ (têxtil e de confecçóes) pelo estado $j$ no $n$-ésimo período;

$X_{j}^{n}=$ representa o valor total das exportaçóes/importaçóes totais no estado $j$ no $n$-ésimo período.

O Índice de Concentração de Produtos (ICP) varia de zero a um. Um valor próximo a 1 corresponde a uma maior especialização ou concentração da pauta exportadora do estado em apenas um produto. De modo contrário, quando o valor do ICP é mais próximo de zero, maior será a diversificação da pauta de comércio das exportaçóes.

Quando um estado tem uma estrutura de exportaçôes concentrada, poderá enfrentar desequilíbrios graves na balança comercial em função de alguma mudança desfavorável ocorrida no setor principal. Sendo assim, uma pauta diversificada pode representar termos de trocas mais estáveis, como abordado por Hidalgo e Da Mata (2004). Então o ICP foi criado para medir o grau dessa fragilidade presentada pelos estados.

\section{b) Índice de Comércio Intrasetorial}

Para analisar a participação do comércio intrassetorial de têxteis e de confecçóes entre os estados e o Brasil, foi utilizado o Índice de Grubel \& Lloyd (1975). Considerando X como o valor das exportaçóes de têxteis e de confecçóes, e $M_{i}$ o valor das importaçóes de têxteis e de confecçóes, temos:

$$
\mathrm{G}-\mathrm{L}=\frac{(\mathrm{Xi}+\mathrm{Mi})-|\mathrm{Xi}-\mathrm{Mi}|}{(\mathrm{Xi}+\mathrm{Mi})}
$$

Onde:

$\left|\mathrm{X}_{\mathrm{i}}-\mathrm{M}_{\mathrm{i}}\right|$ é comércio intersetorial; 
$\left(\mathrm{X}_{\mathrm{i}}+\mathrm{M}_{\mathrm{i}}\right)$ é o comércio total do setor;

$\left(\mathrm{X}_{\mathrm{i}}+\mathrm{M}_{\mathrm{i}}\right)-\left|\mathrm{X}_{\mathrm{i}}-\mathrm{M}_{\mathrm{i}}\right|$ é o comércio intrasetorial.

$\mathrm{O}$ Índice de Grubel e Lloyd pode assumir valores entre 0 e 1. Quanto mais próximo estiver o índice de um, maior a predominância de comércio intrassetorial. De forma contrária, quanto mais se aproximar de zero, maior predominância de comércio intersetorial.

O comércio intrasetorial é o comércio (exportações e importações simultâneas), entre os estados, de mercadorias do mesmo setor. Portanto, ele pode ser explicado por ganhos de escala e diferenciação dos produtos, através do poder de monopólio. Já o comércio intersetorial reflete as vantagens comparativas da economia analisada, ou seja, ocorre quando se tem ganhos em razão do menor custo com os fatores de produção (vantagens comparativas reveladas de H-O). Essa diferenciação do padrão de comércio demonstra a fonte de competitividade do setor.

c) Índice de Hirschman-Herfindahl

O Índice Herfindahl-Hirschman (HHI) também tem como objetivo verificar o grau de concentração do mercado internacional de determinado setor. É definido como a soma dos quadrados da participaçáo de cada estado no mercado através da seguinte equação:

$\mathrm{HHI}=\sum_{i=1}^{n} y_{j}^{2}$

Onde:

$\mathrm{Y}_{j}=$ Participação percentual do estado $j$ no total das exportaçóes/importaçóes.

Quando o índice HHI for igual a um significa uma situação de monopólio. De forma contrária, quando o valor se aproxima de zero significa uma participação melhor distribuída no mercado. O índice HHI foi calculado tanto para medir a concentração das exportaçóes estaduais totais quanto para o setor de têxteis e de confecçóes.

d) Índice de Vantagem Comparativa Revelada

Para analisar competitividade internacional do setor têxtil e de confecçóes no Brasil, se utilizou o índice de vantagem comparativa revelada (VCR). Esse indicador proposto por Balassa (1965) consegue demonstrar se um estado possui vantagem comparativa para determinado setor, comparando sua participação na pauta exportadora nacional.

$$
\mathrm{VCR}=\frac{(\mathrm{Xij} / \mathrm{Xj})}{(\mathrm{Xwi} / \mathrm{X} w)}
$$

Onde:

$\mathrm{X}_{\mathrm{ij}}=$ valor das exportaçóes do setor $i$ (têxteis e confecçóes) no estado $j$;

$\mathrm{X}_{\mathrm{i}}=$ valor total das exportaçóes do estado $j$;

$\mathrm{X}_{\mathrm{wj}}=$ valor das exportações brasileiras $w$ do setor $i$ (têxteis e confecçóes);

$\mathrm{X}_{w}=$ valor total das exportaçóes brasileiras $w$.

A variável $(\mathrm{Xij} / \mathrm{Xj})$ corresponde à participação percentual da exportação estadual de têxteis e de confecçôes em relação à exportação total do estado. De forma semelhante, a 
variável $(\mathrm{Xwi} / \mathrm{Xw})$ corresponde à participação percentual da exportação nacional de têxteis e de confecçóes no total das exportaçóes brasileiras.

Se o índice de vantagem comparativa revelada for mais que 1, então o setor $i$ (têxteis e confecçóes) apresenta vantagem comparativa relevada. Já se o VCR for menor que 1, então o setor $i$ possui desvantagem comparativa revelada.

\section{RESULTADOS E DISCUSSÃO}

De acordo com a metodologia apresentada, procedeu-se com a tabulação do banco de dados e cálculo dos indicadores. Segue os principais resultados, discutidos com base na literatura utilizada.

\section{1 Índice de Gini-Hirschman}

A análise da concentração da pauta das exportaçóes é algo importante a ser discutido, já que regióes com uma estrutura de exportação voltada para produtos primários e, simultaneamente, importaçóes voltadas para produtos mais sofisticados tecnologicamente, podem ter dificuldades em manter seu equilíbrio econômico em relação ao setor externo (Maciel, 2011). Além disso, uma região com um índice elevado de concentração em poucos produtos, fica mais vulnerável a mudanças na demanda externa desses bens (como a alteração nas preferências dos consumidores), sofrendo instabilidade nas receitas cambiais (Lima, 2006).

De acordo com Hidalgo e Da Mata (2004), o Índice de Concentração de Produtos (ICP) é afetado por vários fatores estruturais, como o nível de desenvolvimento econômico, que reflete uma estrutura produtiva mais diversificada, e a presença de um polo comercial, como é o caso do polo têxtil em Pernambuco, que resulta em uma maior diversificação de produtos. Em Pernambuco, conforme citado por Lima (2008), o setor têxtil é comandado pelas empresas Vicunha têxtil e Suape têxtil.

Observando o Gráfico 1, pode-se concluir que a pauta de exportaçóes do Nordeste indicou ser pouco concentrada em relação ao setor têxtil e de confecçóes, pois apresentou um Índice de Concentração de Produtos (ICP) sempre abaixo de 0,106 e decrescente. 
Gráfico 1 - Evolução do Índice de Concentração de Produtos das exportações do setor têxtil e de confecções entre 1997 e 2017

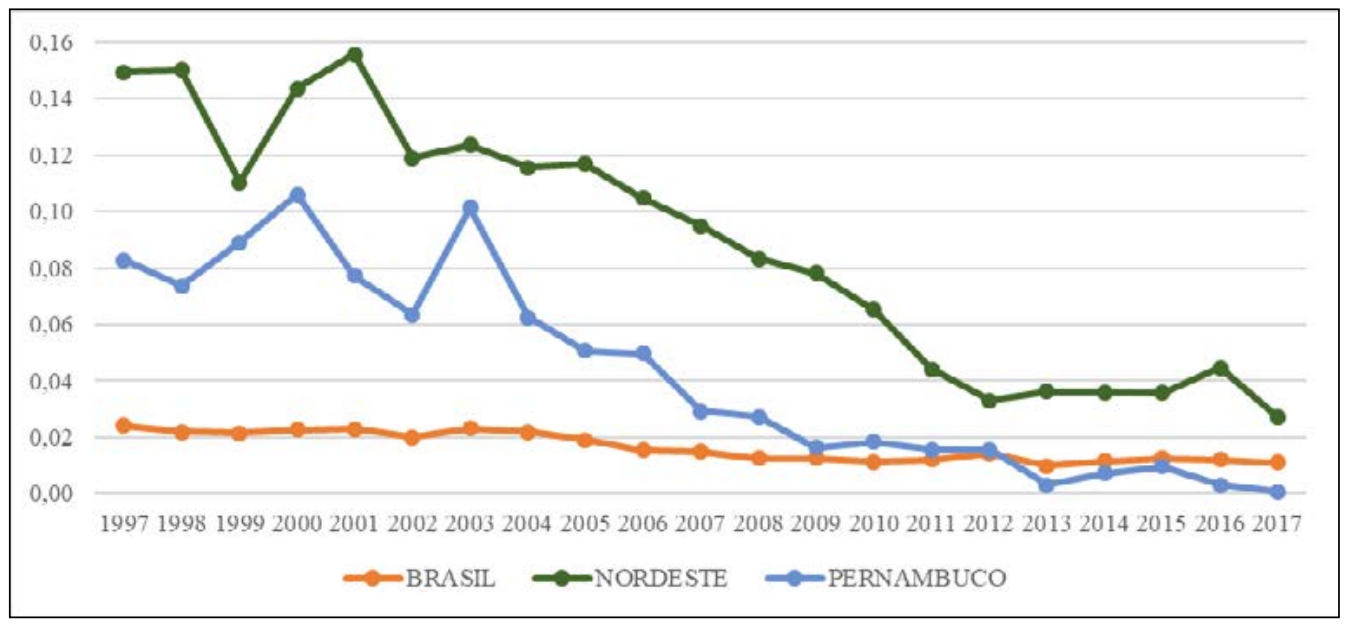

Fonte: Elaboração própria, dados do BRASIL/MDIC/ALICEWEB (2018).

Como pode ser observado, não é possível afirmar que Pernambuco apresentou uma pauta de exportaçóes concentrada no setor têxtil e de confecçóes, onde a média do indicador foi de 0,043 . Outros trabalhos nesta mesma linha como Duarte (2016) e Paganini e Fraga (2014), analisaram todos os setores da Bahia e do Paraná, respectivamente, também constataram relativa diversificação da pauta exportadora. Como conclusão, chegaram que este resultado é reflexo das vantagens comparativas do Estado, conforme sugerido pelos demais indicadores apresentados posteriormente neste estudo.

Ao analisar Pernambuco, Lima (2006) encontrou que o ICP médio para os anos de 2001 a 2005 (considerando todos os setores) foi de 0,3734, um índice maior do que o observado para a concentração do setor têxtil e de confecçóes, que teve média 0,0272 no Brasil no mesmo período. Isso demonstra que esse setor é pouco responsável pela concentração de produtos exportados por Pernambuco. Lima ainda encontrou que o Estado demonstrava uma tendência à redução do indicador, indo de um ICP de 0,4465, em 2001, para 0,3148, em 2005, quando comparado todos os setores. Essa tendência à diminuição também é vista no Gráfico 1, representando o setor têxtil e de confecções, e é acompanhada pela média de concentração do Nordeste como um todo.

Em relação ao Brasil, Costa (2014) encontrou resultados opostos ao analisar o Índice de Concentração de Produtos para exportaçóes em relação a todos os setores (e não apenas o setor têxtil e de confecçóes) entre 1992 e 2011. Em sua pesquisa, o Brasil aponta um índice constante entre 1992 e 2007, mas depois da crise financeira ocorrida dos Estados Unidos, ocorre um significativo aumento no índice ICP, indo de 0,0906 em 2007 para 0,1734 em 2011.

Alguns autores citados por Costa (2014) estudaram como a diversificação da pauta exportadora está relacionada ao crescimento econômico. Costa revelou que os resultados encontrados sugerem que quanto mais concentrada é a pauta exportadora, maior é a 
vulnerabilidade à choques externos. A principal ligação entre diversificação da pauta exportadora e crescimento econômico é a capacidade que os países possuem de se ajustarem à choques externos.

\section{2 Índice de Comércio Intrasetorial}

Os resultados do Índice de Grubel e Lloyd ficaram acima de 0,5 no Brasil, durante todo o período analisado, como é possível observar no Gráfico 2. Isso significa que o comércio internacional brasileiro do setor têxtil e de confecçóes esteve predominantemente caracterizado como intrasetorial, onde o comércio dos produtos ocorre no mesmo setor e é feito com outros países por meio de exportaçóes e importaçóes, simultaneamente. Além disso, esse valor também indica que o País não possui especialização nesse setor.

Diversos estudos têm sido realizados para compreensão do comércio intrasetorial e seus efeitos. Como demonstrado por Ramos Filho e Silva (2016), o setor têxtil brasileiro é um dos que se destacam pelo elevado grau de comércio intrasetorial e espera-se que setores caracterizados por esse comércio tenham baixo custo de realocação, treinamento, etc, para o trabalhador. No entanto, os testes empíricos do estudo não evidenciaram relaçáo entre comércio intrasetorial e reduções nos custos de ajustamento por trabalho, proposição conhecida na literatura como "hipótese de ajuste suavizado".

Gráfico 2 - Índice de Grubel e Lloyd para o setor têxtil e de confecçōes entre 1997 e 2017

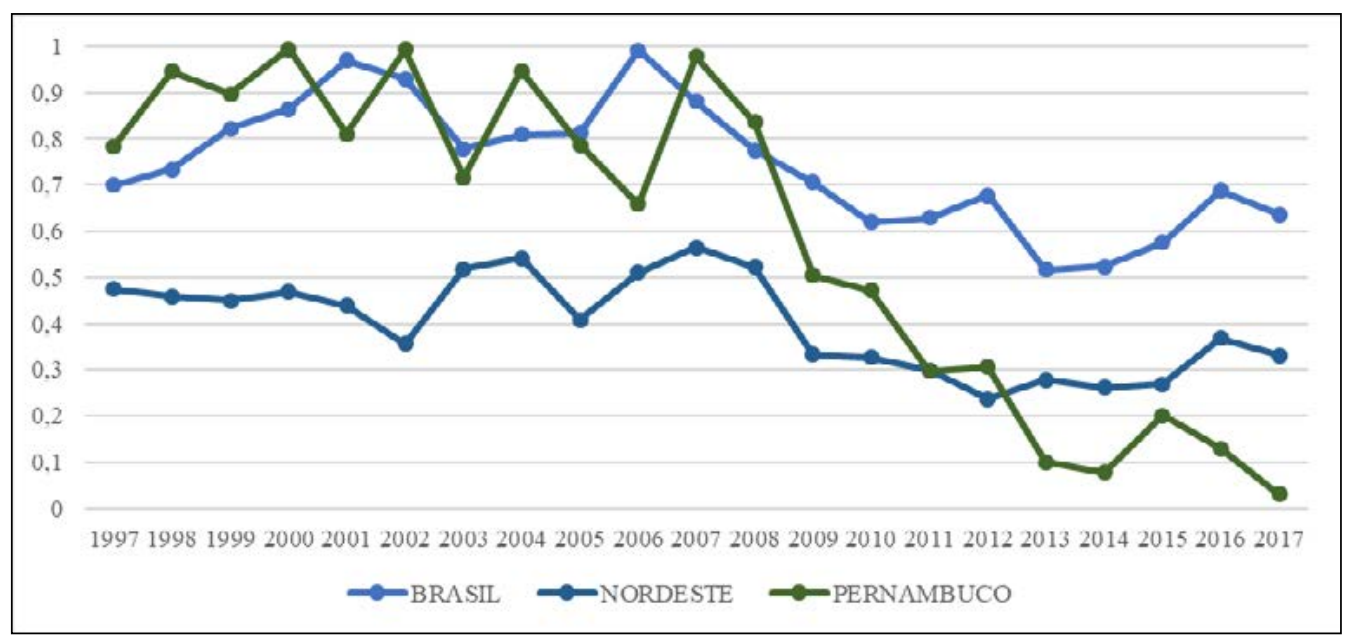

Fonte: Elaboração própria, dados do BRASIL/MDIC/ALICEWEB (2018).

Em Pernambuco, de 1997 a 2009 o comércio era intrasetorial. Maciel (2011) comprovou isso ao encontrar que a média de comércio intrasetorial do grupo têxtil era maior que 0,5 entre 2003 e 2010 e afirmou que Hidalgo e Da Mata encontraram praticamente os mesmos valores para o período de 1996 a 2002.

No entanto, de 2010 a 2017 o comercio em Pernambuco passa a ser caracterizado como intersetorial, demonstrando que o Estado possui vantagem no comércio do setor têxtil e de confecçóes, ou seja, as trocas passaram a ser explicadas pela dotação de fatores e 
pelas vantagens comparativas. Isso pode ser explicado pela diminuição de importações no setor causada pela crise financeira de 2007 nos Estados Unidos, causando a queda do índice

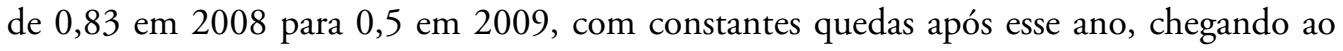
nível de 0,03 em 2017.

Silva et al. (2017) encontrou resultados similares para Pernambuco ao analisar o período de 1999 e 2015, verificando que a partir de 2009 o Estado saiu de um cenário com comércio caracterizado como intrasetorial para um cenário com comércio intersetorial.

\section{3 Índice de Hirschman-Herfindahl}

As exportaçóes brasileiras de todos os setores apresentadas no Gráfico 3 revelaram Índices de Hirschman-Herfindahl (HHI) com valores entre 0,10 e 0,18 , durante o período analisado, enquanto as exportações brasileiras do setor têxtil e de confecções (Gráfico 4) expressaram valores entre 0,12 e 0,22 . De acordo com a classificação do índice, pode-se deduzir que as exportaçóes brasileiras, tanto gerais quanto do setor são moderadamente desconcentradas. Dessa forma, compreende-se que o Brasil possui boa distribuição de suas exportaçóes gerais e do setor têxtil e de confecçôes.

Gráfico 3 - Índice de Hirschman-Herfindahl para o total de exportações entre 1997 e 2017

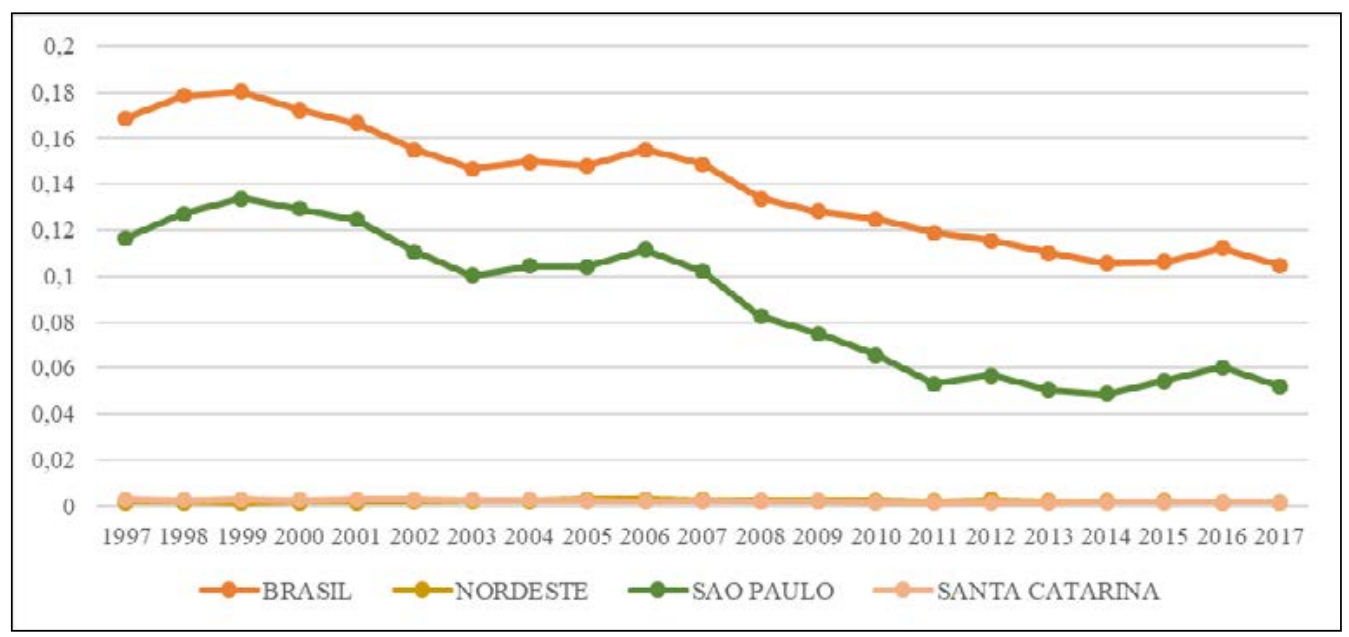

Fonte: Elaboração própria, dados do BRASIL/MDIC/ALICEWEB (2018).

Também é possível observar que as exportaçôes gerais possuem tendência de diminuição de concentração no Brasil. O HHI que era 0,18 em 1999, passou a ser 0,10 em 2017. De forma geral, quando esse índice diminui, significa que existe uma maior competição e menor poder de mercado. Além disso, o Gráfico 3 indica que São Paulo é o Estado com maior participação nas exportaçóes gerais, influenciando os níveis do Brasil (dado pelo somatório de todos os estados). 
Gráfico 4 - Índice de Hirschman-Herfindahl para exportações do setor têxtil e de confecçôes entre 1997 e 2017

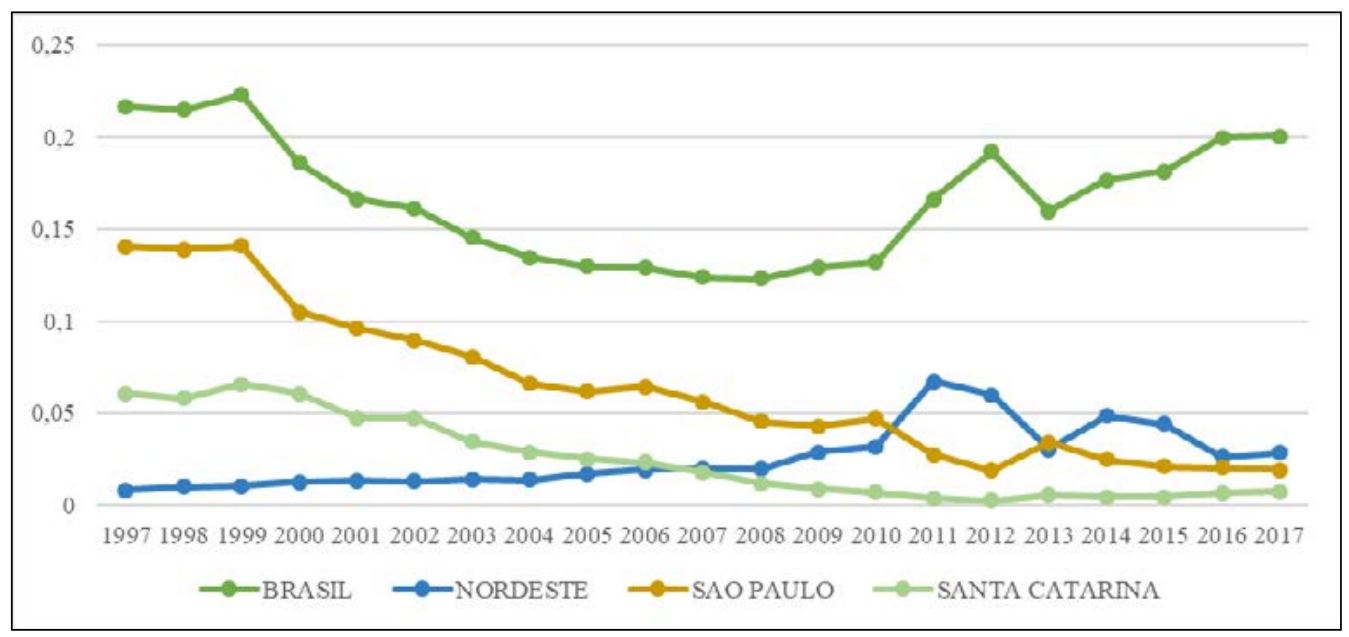

Fonte: Elaboração própria, dados do BRASIL/MDIC/ALICEWEB (2018).

No entanto, a participação de São Paulo, juntamente com Santa Catarina, na exportaçáo do setor têxtil e de confecçóes apresenta diminuição (Gráfico 4), o que significa que esses Estados estáo perdendo poder de mercado no setor. No mesmo período, o somatório da partição dos estados do Nordeste segue uma tendência contrária, indicando decréscimo na competiçáo e aumento no poder de mercado.

Maia Neto (2013) corrobora com os resultados encontrados ao ter analisado o setor de algodáo de forma isolada. O autor encontrou que a pauta de exportaçóes da Região Nordeste era pouco concentrada em relaçáo ao algodão entre 2007 e 2012, havendo um aumento nessa concentração ao longo do tempo vindo do fruto de esforços políticos, presentes principalmente na Bahia e no Piauí, onde a cotonicultura se mostrou bastante relevante em ambos os Estados.

\section{4 Índice de Vantagem Comparativa Revelada}

$\mathrm{O}$ indicador de vantagens comparativas revelada (VCR) demonstra a participação das exportaçôes do setor têxtil e de confecçóes em relação às exportaçóes do Brasil nesse setor, e compara esse quociente com a participação das exportaçóes totais. Dessa forma, um valor de 1,2 indica que a participação de um estado no setor é $20 \%$ maior do que sua participaçáo nas exportaçóes totais. Quando um estado exporta um volume grande de determinado setor, em relação ao que é exportado pelo país nesse mesmo setor, isso sugere que o estado possui vantagem comparativa na produçâao de bens desse setor (LIMA, 2006).

No Gráfico 5 é possível observar que Ceará, Rio Grande do Norte, Paraíba e Bahia possuem vantagem comparativa sobre os demais durante todo período analisado. Enquanto isso, Pernambuco e Sergipe foram perdendo vantagem comparativa ao ponto de passarem a ter desvantagem comparativa ao longo dos anos e Piauí apresenta índices inconstantes. $\mathrm{O}$ 
Estado que apresenta a maior vantagem comparativa revelada média é a Paraíba. O destaque deste Estado provavelmente dá-se em razão da produção de algodão, inclusive com uma parte beneficiada pela Embrapa, tornando-se o único produtor brasileiro de algodão colorido. As peças de vestuário produzidas com o algodão colorido, ambientalmente sustentável, são bem vistas no mercado internacional. Portanto, o País teria aí um nicho de mercado a explorar.

Gráfico 5 - Índice de Vantagem Comparativa Revelada entre 1997 e 2017

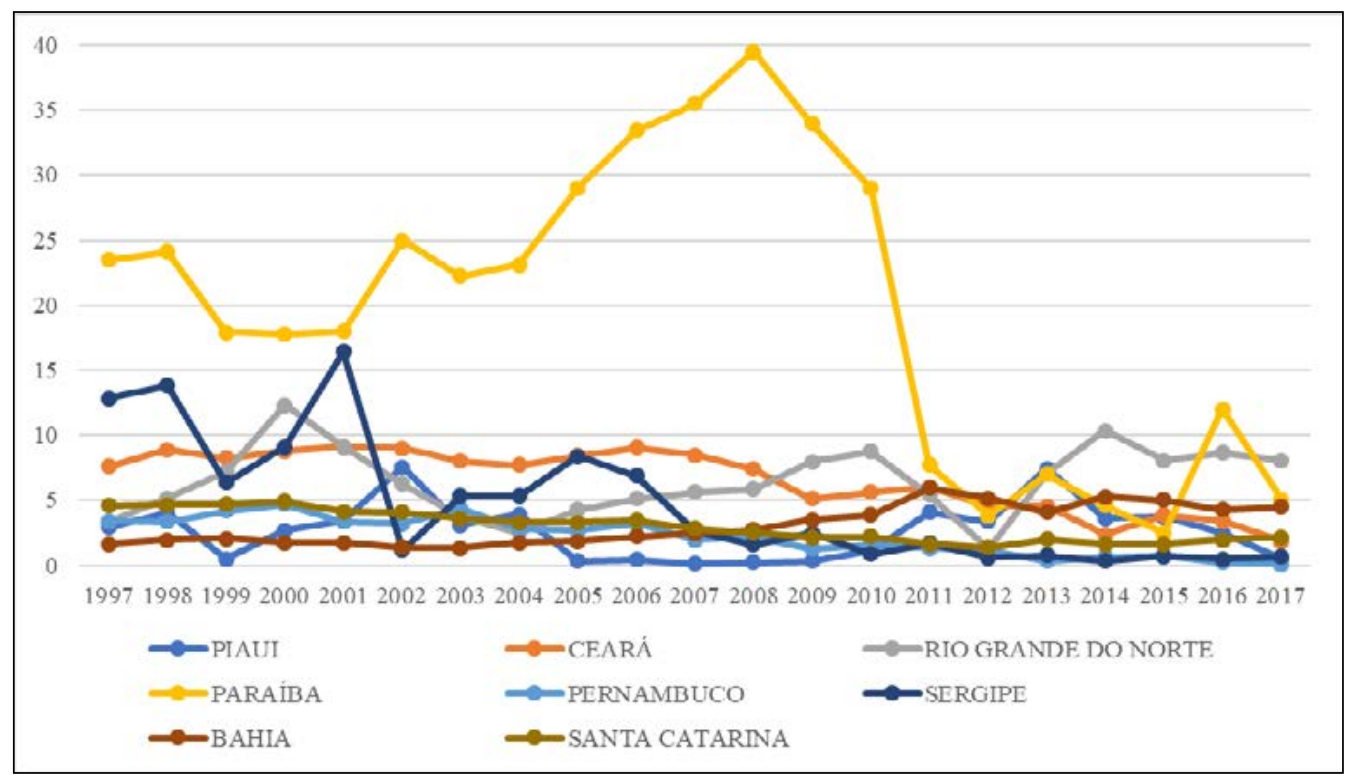

Fonte: Elaboração própria, dados do BRASIL/MDIC/ALICEWEB (2018).

Maranhão e Alagoas não foram inseridos no Gráfico 5 por apresentarem desvantagem comparativa em quase todos os anos analisados. Fora do Nordeste, um estado com destaque no setor é Santa Catarina, apresentando um índice de vantagem comparativa relativamente constante.

Franck et al. (2017) estudaram o padrão de especialização do comércio internacional de Alagoas, e para isso calcularam diversos índices, dentre eles o índice de vantagens comparativas reveladas simétricas. Foram analisados 14 setores (incluindo o setor têxtil), onde apenas o setor de alimentos, fumo e bebidas apresentou vantagem comparativa no período. Com isso os autores concluíram que o Estado tem pauta produtiva com pouca diversificação, o que pode indicar uma vulnerabilidade às oscilações de variáveis externas (mudança de preços internacionais, crises) e internas (estiagens).

Machado (2014), ao estudar os determinantes das vantagens comparativas reveladas para a Paraíba, entre 2000 e 2013, encontrou valores similares para o índice, onde o setor têxtil e de confecçóes obteve vantagem por todo o período, porém desde 2011 o setor passou a apresentar diminuição no índice de vantagem. Como demonstrado pelo autor, o que pode justificar a Paraíba ter o maior índice do Nordeste até 2011 é o fato do setor ter 
representado, entre 2002 e 2007, mais de 50,00\% das exportaçóes totais paraibanas, e a partir de 2011 a participação do setor caiu para menos de 10,0\%.

Esses resultados foram confirmados por Lima (2006), que calculou o VCR para Bahia, Ceará e Pernambuco para diversos agregados no período de 2001 a 2005 e encontrou valores praticamente iguais, concluindo que os três Estados possuíam VCR no setor têxtil. $\mathrm{O}$ autor ainda observou que a participação de calçados e têxteis (intensivos em máo-deobra) no PIB cearense era cada vez maior e que em Pernambuco existia uma dualidade na "predominância de setores tradicionais (açúcares, intensivo em mão-de-obra e recursos naturais) com os emergentes (frutas e gesso, intensivos em recursos naturais, e plásticos e borrachas, intensivo em capital)".

Da mesma forma, Maciel (2011) também encontrou que Pernambuco possui vantagem comparativa revelada no setor têxtil, ao analisar o período de 2003 a 2010, para diversos grupos. A autora também percebeu que esse grupo estava tendo cada vez menos vantagem comparativa revelada, e que esse fato poderia ser explicado pelo fato do Estado estar perdendo mercado exportador no setor para a China, por causa dos seus baixos preços. Dando continuidade à perda de vantagem comparativa observada por Maciel (2011), foi encontrado que, a partir de 2013, Pernambuco passou a ter desvantagem comparativa no setor.

\section{CONCLUSÓES E DISCUSSÓES}

Levando em conta a atual situação do setor têxtil e de confecções brasileiro, essa pesquisa teve como principal objetivo analisar a competitividade das exportaçóes desse setor, com foco no Nordeste e em Pernambuco. Para isso, calculou-se indicadores de competitividade consagrados na literatura sobre comércio internacional: Índice de GiniHirschman, Índice de Comércio Intrasetorial, Índice de Hirschman-Herfindahl e Índice de Vantagem Comparativa Revelada.

Em um contexto de liberação comercial, a partir da década de 1990, a globalização do mercado doméstico foi desafiante para o Brasil, que não tinha planejamento para lidar com essas mudanças e se mostrou um País fragilizado. Além disso, no setor têxtil e de confecçóes, o Brasil enfrenta uma invasão de produtos importados asiáticos, onde a China aparece como líder mundial em exportaçóes no setor, diminuindo a vantagem comparativa revelada deste setor.

O estudo demonstrou que o Nordeste não tem uma pauta de exportaçóes concentrada no setor têxtil e de confecções, o que era esperado, já que a Região concentra suas exportaçóes em commodities agrícolas e minerais. Ainda, o comércio internacional brasileiro do setor é caracterizado por ser predominantemente intrasetorial no período analisado, de 1997 a 2017, significando que comércio do Brasil se fundamenta, principalmente, na existência de economias de escala, concorrência imperfeita e diferenciação dos produtos. Já Pernambuco, de 2010 a 2017, passa a ter um comércio intersetorial, seguindo os preceitos da teoria de Heckscher-Ohlin, em que a especialização está baseada na dotação de fatores de cada país.

Ademais, São Paulo se mostrou o Estado com maior participação nas exportações gerais, influenciando os níveis do Brasil, enquanto o Nordeste indica um aumento no 
poder de mercado no setor têxtil e de confecções, o que pode ser justificado pelo fato de grande parte dos estados da Regiáo possuírem vantagem comparativa no setor durante todo período analisado, com exceção de Pernambuco e Sergipe que foram perdendo vantagem comparativa e passaram a ter desvantagem comparativa ao longo dos anos.

Os índices permitem concluir que desde a abertura da economia brasileira, o Estado de Pernambuco e o Nordeste como um todo náo aproveitam muito bem as oportunidades que o comércio tem a oferecer. Existe uma necessidade de expansão de investimento no setor, para se adquirir maior produtividade e competitividade frente ao mercado internacional. Além disso, acordos comerciais bilaterais com o Nordeste e países pequenos ajudaria a criar mais rotas comerciais, o que aliviaria os efeitos da China.

Para estudos futuros, pretende-se identificar alguns nexos de causalidade entre a forma que adquire a matriz de competitividade ao longo do tempo e as caraterísticas do mercado chinês, tal como realizado por Fernandes e Curado (2016), tendo como diferencial o objeto de estudo, considerando o impacto chinês sobre o mercado internacional brasileiro no comércio com os países do Mercosul. Outra questão específica a ser considerada continuará sendo o foco no setor têxtil e de confecçóes, ainda que observar a dinâmica de outros setores possa ser importante para explicar questôes de competitividade dessas economias.

\section{REFERÊNCIAS}

ABIT. Perfil do Setor. Disponível em: <http://www.abit.org.br/cont/perfil-do-setor>. Acesso em: 20 jul. 2018.

ALICEWEB, Sistema de Análise das Informaçóes de Comércio Exterior. Disponível em: http://aliceweb.mdic.gov.br/. Acesso em: fevereiro 2018.

AMATO NETO, J. Redes de cooperaçáo produtiva e clusters regionais oportunidades para as pequenas e médias empresas. São Paulo, Atlas/Fundação Vanzolini, 2000.

BALASSA, BELA. Revealed comparative advantage revisited: analysis of relative export share of industrial countries, 1953-1971. Manchester School of Economic and Social Sudies, Manchester, Manchester University Press, v.45, p. 327-44, 1977.

BONELLI, R.; PINHEIRO, A.C. Competitividade e desempenho industrial: além do câmbio. FGV/IBRE (Texto para Discussão), 2012.

BRADESCO. Têxtil e confeç̧óes. Departamento de Pesquisas e Estudos Econômicos do Bradesco, 2017.

CALDEIRA, A. et al. Estratégias de cooperação para a competitividade no setor têxtil brasileiro: o papel de entidades de classe. Revista eletrônica sistemas \& gestáo, v. 12, n. 3, p. 295-307, 2017. 
COSTA, K.G.V. Fragmentação internacional da produção e sofisticação das exportaçôes: uma análise a partir dos fluxos de comércio do Mercosul entre 1994 e 2012. In 42。 Encontro Nacional de Economia - ANPEC, Anais... Florianópolis, RN, 9 A 12 de dez 2014.

COSTA, L.V et al. Comportamento e padrão de especialização do fluxo industrial de comércio exterior do Paraná, 1996 a 2008. Revista de Economia, Editora UFPR, v.38, n.3 (ano 36), p.7-29, set/dez 2012.

DUARTE, Leandro Batista. Especialização e competitividade do comércio exterior da bahia (2005-2016). Revista debate econômico, [S.L.], v. 4, n. 2, p. 53-69, jul./dez. 2016.

FILHO, Hélio Sousa Ramos; SILVA, Helayne Izabel Carlos Ribeiro. Comércio intraindústria e os ajustamentos no mercado de trabalho brasileiro: uma análise setorial usando dados em painel. Revista de economia, Universidade federal do paraná, v. 43, n. 2, mai./ ago. 2016.

FONTENELE, A. M.; MELO, M.C.P. Inserçáo Internacional da Economia Cearense: Potencialidades e Limites para o Crescimento. Fortaleza: Banco do Nordeste S.A., 2003.

FÓRUM ECONÔMICO MUNDIAL. Reports. Disponível em: <https://www.weforum. org/>. Acesso em: 20 fev. 2018.

FRANCK, A. G. S. et al. Padrão de especialização do comércio internacional de alagoas (1999-2016). Revista observatorio de la economía latinoamericana, Brasil, mai. 2017.

FURTADO, Celso. Formaçáo econômica do Brasil. 34. ed. São Paulo: Companhia das Letras, 2007.

GALVÃO, Olímpio J. de A.; VERGOLINO, José Raimundo O. O Comércio e a Inserção Competitiva do Nordeste no Exterior e no Brasil. Fortaleza: Banco do Nordeste do Brasil, 2004.

GONÇALVES, Reinaldo. A nova economia internacional: uma perspectiva brasileira. Rio de Janeiro: Campus, 1998.

GRUBEL, H.G.; LLOYD, P.J. Intra-industry trade: the theory and measurement of international trade in differentiated products. London: MacMillan Press, 1975.

HIDALGO, Álvaro; MATA, Daniel da. Inserção das regiões brasileiras no comércio internacional: os casos da Região Nordeste e do Estado de Pernambuco. Revista Econômica do Nordeste, Fortaleza, v.35, n.2, abr/jun.2004. 
INTERNATIONAL MONETARY FUND (FMI). World economic outlook: subdued demand - syntoms and remedies. World Economic and Financial Surveys, oct 2016.

KELLER, Paulo Fernandes. Impactos da globalizaçáo econômica sobre a cadeia têxtil brasileira: O caso do polo têxtil de Americana (SP). Revista Universidade Rural, Série Ciências Humanas. Seropédica, RJ, EDUR, v. 28, n. 1, p. 59-77, jan.-dez., 2006.

KUPFER, D.; HASENCLEVER, L. Economia industrial - fundamentos teóricos e práticas no Brasil. Campus, 2013.

KRUGMAN, P. Are currency crises self-fulfilling? Bureau of Economic Research. MIT Press, 1996.

KRUGMAN, Paul R.; OBSTFELD, Maurice. Economia internacional. 8. ed. São Paulo: Pearson Education do Brasil, 2009.

LIMA, R.S. Inserçáo internacional do Nordeste brasileiro: o caso da Bahia, Ceará e Pernambuco. Dissertaçáo - Programa de Pós-Graduação em Economia - PIMES. Curso de Mestrado Profissional em Economia: Área de Comercio Exterior e Relações Internacionais / Universidade Federal de Pernambuco - UFPE, 2006.

LIMA, M.G.; LÉLIS, M.T.C. Comércio internacional e comportamento no Brasil: um estudo comparativo utilizando a metodologia Constant-market-share para o período de 2000-2011. Economia e Sociedade, Campinas, v.24, n.2 (54), p.419-448, ago 2015.

LINS, Julyan Gleyvison Machado Gouveia. Um estudo sobre a concentraçáo espacial do emprego nos setores de confecçóes e couro-calçadista no nordeste do Brasil, 2015. 81 f. Dissertação (Mestrado em Economia) - Universidade Federal da Paraíba, João Pessoa, 2015.

MACHADO, Thiago De Queiroz. Exportaçóes paraibanas entre 2000 e 2013: estudo de determinantes de vantagens comparativas reveladas. Monografia. Curso de Graduação em Economia. Universidade Federal da Paraíba, João Pessoa, 2014.

MACIEL, T.F. Relaçóes comerciais entre Pernambuco e o Resto do Mundo (20032010). Dissertação - Programa de Pós-Graduação em Economia - PIMES. Curso de Mestrado Profissional em Economia: Área de Comercio Exterior e Relaçốes Internacionais / Universidade Federal de Pernambuco - UFPE, 2011.

MAIA NETO, P.L. Caracterizaçáo, possibilidades e limitaçóes do mercado do algodáo no Brasil. Dissertação - Programa de Pós-Graduação em Economia - PPGECON (Orientado pela Professora Monaliza Ferreira). Curso de Mestrado em Economia/ Universidade Federal de Pernambuco - UFPE, Campus Acadêmico do Agreste, 2013. 
MEDEIROS, C. A China como um duplo polo na economia mundial e a recentralização asiática. Revista de Economia Política, v. 26, p. 381-400, 2008.

MARSHALL, A. Princípios de economia. São Paulo: Abril Cultural, 1985.

MUNDURUCA, F. V.; SANTANA, J. R. de. Comércio Exterior como Estratégia de Crescimento Econômico: Uma Proposta de Priorização de Produtos Exportáveis para a Economia Sergipana. Banco do Nordeste do Brasil (BNB). Documentos Técnicos Científicos. Volume 43, No 03, 2012.

PAGANINI, Caio Cezar; FRAGA, Gilberto Joaquim. Padrão de Especialização do Comércio Internacional do Paraná no Período 2001-2011. Revista Paranaense de Desenvolvimento-RPD, v. 35, n. 127, p. 135-154, 2014.

PORTER, M. Estratégia competitiva. Rio de Janeiro: Campus, 1999.

PROCÓPIO, D. P.; CORONEL, D. A.; LÍRIO, V. S. Competitividade do mercado internacional de carne bovina: uma análise dos mercados brasileiro e australiano. Revista de Política Agrícola, v. 20, n. 2, p. 40-51, 2011.

RICARDO, D. Princípios de economia política e tributaçáo. Tradução de Paulo Henrique Ribeiro Sandroni. São Paulo: Nova Cultural Ltda., 1996.

SALVATORE, Dominick. Introduçáo à Economia Internacional. Rio de Janeiro: LTC, $1^{\circ}$ ed. 2007.

SAQUIS, S.J.B. Comércio internacional e crescimento econômico no Brasil. Fundação Alexandre Gusmão. Brasília, 2011. .248p.

SILVA, R. A. da et al. Padrão de especialização do comércio internacional de Pernambuco (1999-2015). Revista de administraçáo e comércio exterior, Santa maria, rs, v. 3, n. 2, p. 2-23, 2017.

TEIXEIRA, Francisco MP. A história da indústria têxtil paulista. Sinditêxtil-SP, 2007.

WILLIAMSON, John. A Economia Aberta e a Economia Mundial: um Texto de Economia Internacional. Rio de Janeiro; Campus, 1989.

WOOD JR, T.; CALDAS, M.P. Empresas brasileiras e o desafio da competitividade. RAE, v.47, n.3, jul/set 2007. 